\title{
Grounding System Design in Electrical Substation: An Optimization Approach
}

\author{
H. M. Khodr, Member, IEEE, G. A. Salloum, and Vladimiro Miranda, Fellow, IEEE
}

\begin{abstract}
The main purpose of this work is the development of an optimization model for the design of the grounding grid in electrical substations. The problem is formulated as a mixedinteger linear programming problem, in terms of the constructive characteristics and the peculiar requirements to construct and to install the grounding grid. The model incorporates the variables that define the grid characteristics of all possible configurations including the grid geometry and the depth and conductor size. The optimization problem is subject to safety constraints related with the maximum allowed touching and step voltages. It also includes the equivalent impedance of the transmission line connected to the substation where it will be located the grounding grid to be designed. The methodology allows selecting the optimum grid of the possible configurations, so that is a very useful tool for the engineering design. The formulation and specifications used is based in IEEE Std. 80-2000.
\end{abstract}

Index Terms--Engineering Design, Grounding System, Linear Programming, Optimization

\section{NOMENCLATURE}

$\Gamma_{K}$ Cost Coefficient associated to "k" size conductor.

$\alpha_{K}$ Cost Coefficient " $\alpha$ " associated to Accessory cost of the conductor with size " $k$ ".

$\beta_{K}$ Cost Coefficient " $\beta$ " associated to Accessory cost of the conductor with size "k".

$\chi \quad$ Cost Coefficient associated to excavation.

$\psi \mathrm{g}$ Cost Coefficient associated with the "g" rods considered in grid design.

$\lambda_{w}$ Cost Coefficient associated to "w" complementary electrodes used to ground the transmission lines.

$C_{l}^{T}$ Cost Coefficient investment associated to the of the construction grounding grid.

$C_{2}{ }^{T}$ Cost Coefficient investment associated with the construction of the grounding transmission line.

$\mathrm{E}_{\mathrm{STTEP}, \mathrm{j}, \mathrm{k}, \mathrm{g}, \mathrm{f}, \mathrm{q}}$ Step voltage calculated for each grid configuration.

This work has been supported in part by Fundação para a Ciência e a Tecnologia Grant SFRH/ BPD/ 21035/ 2004. 1

H. M. Khodr is with INESC Porto on leave of Energy Conversion and Delivery Department, Universidad Simón Bolívar, Aptdo.89000, Caracas, Venezuela (e-mail: hkhodr@usb.ve).

G. A. Salloum is with INELECTRA C.A., Caracas, Venezuela.

V. Miranda is with the Instituto de Engenharia de Sistemas e Computadores do Porto (INESC Porto), University of Porto, Porto 4200-465, Portugal (e-mail: vmiranda@inescporto.pt).
$E p_{i, j, k, g, f, q}$ Real Variable associated with the calculated Step Voltage for each grid configuration and complementary electrode.

$\mathrm{E}_{\text {STEP }}{ }^{\mathrm{MAX}}$ Maximum allowed Step Voltage.

$\mathrm{E}_{\text {Touchi,j,k,g,f, }}$ Touch voltage calculated for each grid configuration.

$\mathrm{E}_{\text {точсн }}{ }^{\text {MAX }}$ Maximum allowed Touch Voltage.

$\mathrm{E}_{\mathrm{t} \mathrm{i}, \mathrm{j}, \mathrm{g}, \mathrm{f}, \mathrm{q}}$ Real Variable associated with the calculated Touch Voltage for each grid configuration and complementary electrode.

Rg Grounding grid resistance

$\mathrm{X}_{\mathrm{i}, \mathrm{j}, \mathrm{k}, \mathrm{g}, \mathrm{f}}$ Integer decision Variable associated with the grounding grid installation.

$\mathrm{Y}_{\mathrm{q}, \mathrm{w}}$ Integer decision Variable associated with the installation of the complementary electrodes.

Zeq $_{\text {LINE }}$ Equivalent impedance of the transmission line

Zeq $_{\mathrm{q}, \mathrm{w}}$ Equivalent impedance of the complementary electrodes of the transmission line.

$\mathrm{i}, \mathrm{j}, \mathrm{k}, \mathrm{g}, \mathrm{f}, \mathrm{w}$ integer indices.

\section{INTRODUCTION}

$\mathrm{G}$ rounding system is one of the most important points inside the transmission systems and electric power distribution design. The main purpose of power system substation grounding grids is to maintain reliable operation and provide protection for personnel and apparatus during fault conditions. Grounding system allows controller harmonics and drain to earth the fault currents.

A good grounding grid design should be able to maintain the touch and step voltages inside the substation in permissible limits, which are defined based on fibrillation discharge limit. Due to the non uniformity of soil and measuring error of soil resistivity data and some other factors which cannot be considered in simulating calculations, the designed value of the grounding system impedance must be checked by the measured one after the grounding system is constructed, on the other hand, exist any variables that are in many cases established for designer. The design methods and simplified calculation can originate high construction cost, combining high construction and insecure conditions. The appropriate design methods minimize time and cost construction and they offer great reliability in obtained results [8] [13][16] [17].

In this work a mathematical model has been developed, it' $\mathrm{s}$ based on grounding system grid design model [16] and grounding transmission line model [9] outlines and solve an 
optimization problem that allows a grounding grid configuration selection including geometry, depth and conductor size of a universe possible solutions. Additionally the model allows selecting a complementary electrodes system for transmission line of the feasible solutions space. This selection is obtained for the condition of minimum investment cost fulfilling system technical and safety constraints (touch and step voltage allowed).

The developed mathematical Model allows elaborating a database with all the parameters of the system, including all the grid configurations and all possible complementary electrodes, outlining a linear mathematical model where the decision variables are binary.

The mathematical problem is solved adequately by means of application of linear optimization technique (branch and bound) using the commercial platform LINDO [10][11]. Touch and step voltage calculation is carried out in conformity with the recommended methodology explained in Standard IEEE-80 - 2000 [16].

The problem associated with the grounding system grid construction in substations has been studied by many investigators that have looked for to optimize the grid design to explain the essential technical problems [1] [2] [3] [4] [14] [15].

Some investigators have studied the grounding system design problem in search of the more efficient of the best behavior grounding system grid, taking in to considerations bistratified and multi-stratified soils [3], induced voltage [5], and fault currents [6] [7] among other, establishing some costbenefit approaches.

\section{FIELD OF APPLICATION}

The proposed methodology can be used for all the grid geometries considered in the Standard IEEE std. 80-2000 with the premises that are indicated in this standard; this is due to that this work is coherent with the standard before mentioned and the universal optimization techniques of linear programming .

The costs calculations for the different grid configurations and the complementary electrodes indicated in outlined methodology turns out very simple and can be carried out with the help of an Excel Program. In consequence, a data sheet that only requires to be upgraded and to be adjusted to the new materials cost in each created project.

The Linear programming technique package LINDO [11], is universal, due this the proposed methodology can be adapted to other available packages of linear programming existed in the market.

With the base to the above-mentioned, the methodology outlined in this paper posse the same application field that the IEEE std. 80-2000.

This paper opens up a route to other investigations associated to the topic, due that only linear optimization is used. Non-linear optimization would be used take into account all variables in the design of non-linear nature as soil resistivity, in consequence other programs accessible in the market for this purpose would be used .

Other element interesting for consider is the grounding in the course of all the transmission lines considering too lightning influence according to local resistivity of the soil.

Two components of objective function outlined in this model are associated to: Grounding grid and the complementary electrodes construction cost.

\section{Proposed Methodology}

For a given area, different grid configurations can settle down with different spacings between conductors varying their geometry.

In the design takes into account the part from the fault current that returns to transmission line that feeds to the substation.

For the given characteristics of the grounding grid design, that is: soil equivalent resistivity, rock-crash superficial resistivity, rock-crash superficial thickness, grid area, clearance time of fault current, ambient temperature and line equivalent grounding impedance; is conserved as cost variables associated to grounding grid: the conductor size, geometry, rod numbers and depth grid.

The variable cost is considered too the elements associated to complementary electrodes of transmission line, in consequence is consider variable all different configurations selected by designer.

The mathematical model is established for the optimum selection of grounding grid configuration, they are defined some Integer-binary decision variables $\mathrm{X}_{\mathrm{i}, \mathrm{j}, \mathrm{k}, \mathrm{g}, \mathrm{f}}$ that correspond to the decision of to build a grounding grid with geometry, conductor size, rod and depth certain. In this way, optimization problem consists on determining the grid characteristics for the condition of minimum investment cost fulfilling the required technical restrictions.

In the mathematical model optimal selection of complementary electrodes is considered, they are defined some Integer-binary decision variables $Y_{w}$ that correspond to the decision of to build an electrode $Z_{w}$ in the last tower of the transmission line (make a parallel of the line equivalent impedance). In this way, optimization problem consists on determining, for each electrode, the geometry for the condition of minimum investment cost minimizing the equivalent impedance of the transmission line and with it minimizing too the fault current Dividing Factor $\mathrm{S}_{\mathrm{f}}$.

In the figure 1 is presented the general diagram used for implement the proposed methodology.

\section{Mathematical Model}

General optimization model consists on cost function minimization of lineal nature with integers and binaries decision variables (values 0 or 1 ).

The problem may be stated as an optimization problem as an objective function representing the fixed costs correspondent to the investment in grounding grid and complementary electrodes: 
Subject to the following constraints: ; With $w \neq 0$ 1. - Alone can choose a grounding grid configuration

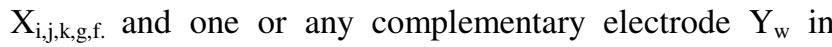
function of touch voltage allowed.

2. - Alone can choose a grounding grid configuration $X_{i, j, k, g, f .}$ and one or any complementary electrode $Y_{w}$ in function of the allowed Step Voltage.

3. - Touch Voltage calculated should not exceed the value $\mathrm{E}_{\text {touch }}{ }^{\max }$ established by the designer in function to the allowed Touch Voltage.

4. - Step Voltage calculated should not exceed the value $\mathrm{E}_{\text {touch }}{ }_{\max }$ established by the designer in function to the allowed Touch Voltage.

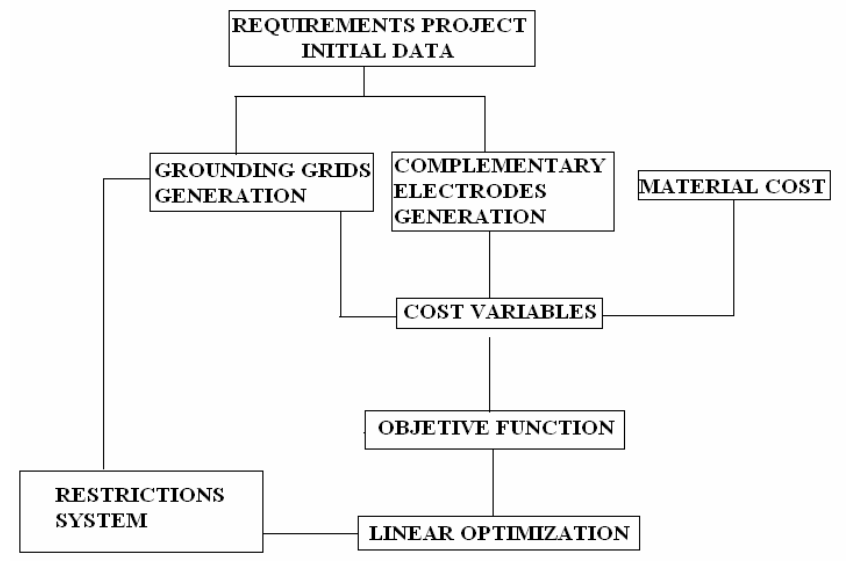

Fig.1. Methodological general diagram

The objective function consists on minimizing the installation costs associated to the grounding grid and complementary electrode, expressed by the following equation:

$$
\operatorname{Min}\left[\sum_{f} \sum_{g} \sum_{k} \sum_{j} \sum_{i} C_{1}{ }^{T} X_{i, j, k, g, f}+\sum_{w} C_{2}{ }^{T} Y_{w}\right]
$$

This equation represents the cost decision variables with cost coefficient. The subscript (i, j, k, g, and f) represents the design considerations to optimize (conductor size, geometry, depth and rods). Designers can use other parameters in design for considering but these variables should be of linear nature.

Subject to the following constraints:

A. Grounding grid and complementary electrodes selection in function with step voltage:

$$
\begin{aligned}
& \sum_{f} \sum_{g} \sum_{k} \sum_{j} \sum_{i} X_{i, j, k, g, f}-V p_{i, j, k, g, f, w}=0 \\
& \sum_{W} X_{W-} V p_{W}=0 \quad ; \text { With } \quad \mathrm{w} \neq 0
\end{aligned}
$$

B. Grounding grid and complementary electrodes selection in function with touch voltage:

$\sum_{f} \sum_{g} \sum_{k} \sum_{j} \sum_{i} X_{i, j, k, g, f}-V t_{i, j, k, g, f, w}=0$

$\sum_{W} X_{W-} V t_{W}=0$
Grounding grid and complementary electrodes selection is carried out by means fulfillment of allowed voltages, in such way that those configurations that no fulfillment with these restrictions are discarded.

Then, the configurations that have not been discarded are selected in function of their associate costs using the branch and bound mixed-integer linear programming technique.

C. For each grounding grid configuration $X i, j, k, g, f$. and complementary electrode $Y q, w$ exist a step voltage associated):

$\sum_{w} \sum_{f} \sum_{g} \sum_{k} \sum_{j} \sum_{i}$ EStep $_{i, j, k, g, f}\left(Z_{w}\right)=E p_{i, j, k, g, f, w}$

Where:

$$
Z_{w}=\frac{Z e q_{w}}{Z e q_{\text {LINEA }}}\left(\frac{Z e q_{\text {LINEA }}+R}{S e q_{W}+R}\right) Y_{w}
$$

For all $\mathrm{w} \neq 0$ and $\mathrm{Z}_{\mathrm{w}}=1$, for $\mathrm{w}=1$

$Z_{w}$ is calculated for establish the influence of complementary electrodes in grounding resistance that affect the step voltage.

This consideration is necessary due to that multiples combination of grounding grid (to different depth, multiples rods, various conductors sizes and geometries) and electrodes complementary (different configuration of electrodes or electrodes system) origin multiples solutions for grounding resistance, in consequence step voltage calculated should be considered in each case and fulfill with the allowed step voltage.

If any surpasses the allowed step voltage is not consider problem solution, in such way that the methodology discard all configurations (ground grid and/or complementary electrodes) that no fulfill with this constraint.

D. System constraint (maximum allowed Step voltage):

$\sum_{w} \sum_{f} \sum_{g} \sum_{k} \sum_{j} \sum_{i} E p_{i, j, k, g, f, w}-E_{\text {STEP }}^{M A X} \leq 0$

Constraints $C$ and $D$ establish the relationship between allowed step voltage and calculated step voltage, including the influence of complementary electrodes used or not on the last transmission tower.

E. For each grounding grid configuration $X i, j, k, g, f$. and complementary electrode $Y q, w$ exist a associated touch voltage):

$\sum_{w} \sum_{f} \sum_{g} \sum_{k} \sum_{j} \sum_{i}$ Etouch $_{i, j, k, g, f}\left(Z_{w}\right)=E t_{i, j, k, g, f, w}$

Where:

$Z_{w}=\frac{Z e q_{w}}{Z e q_{\text {LINEA }}}\left(\frac{Z e q_{\text {LINEA }}+R_{g}}{Z e q_{W}+R_{g}}\right) Y_{w}$

for all $w \neq 0$ and $Z_{w}=1$, for $w=1$

$Z_{w}$ is calculated for establish the influence of complementary electrodes in grounding resistance that affect the touch voltage.

This consideration is necessary due to that multiples combination of grounding grid and electrodes complementary 
origin multiples solutions for grounding resistance, in consequence touch voltage calculated should be considered in each case and fulfill with the allowed touch voltage.

If any surpasses the step allowed is not consider problem solution, in a such way that the methodology discard all configurations (ground grid and/or complementary electrodes) that no fulfill with this restriction

F. System restriction (maximum allowed Step voltage):

$\sum_{w} \sum_{f} \sum_{g} \sum_{k} \sum_{j} \sum_{i} E t_{i, j, k, g, f, w}-$ Etouch ${ }^{\text {MAX }} \leq 0$

Constraints $E$ and $F$ establish the relationship between the allowed touch voltage and the calculated step voltage, including the influence of complementary electrodes used or not on the last transmission tower.

Once the geometries of grounding grid have been defined, proceeds to calculation of all necessary cost for its construction as conductors, accessories, excavation and filler volume as well as perforation length.

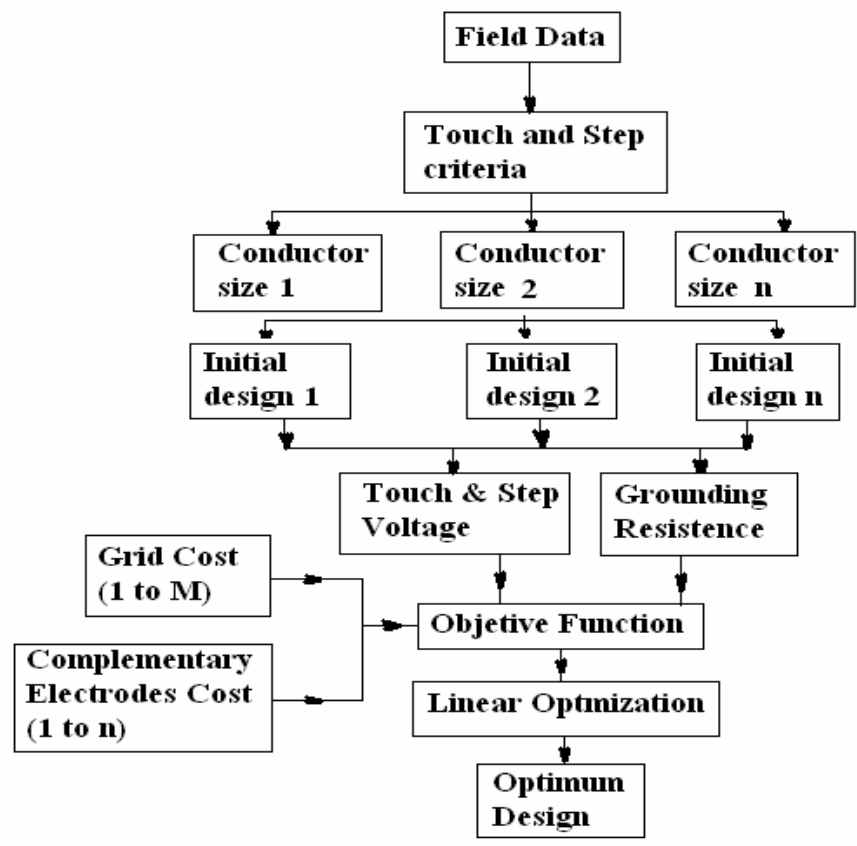

Fig.2. Proposed methodology diagram outline for grounding grid design.

These parameters are used for obtain the costs $\mathrm{C}_{1}{ }^{\mathrm{T}}$ and $\mathrm{C}_{2}{ }^{\mathrm{T}}$ associated to the objective function in equation 1 as following: $C_{1}^{T}=[(i+1) l+(j+1) L] \cdot \Gamma_{k} \cdot[1+0.25 \cdot f \cdot \chi]+\left[\alpha_{k} \cdot(2 i+2 j)+\beta_{k}(i j-i-j+1)\right]+\psi_{g}$

$$
C_{2}{ }^{T}=\lambda_{w}
$$

To solve the optimization problem before outlined a commercial computational package denominated LINDO is used (Linear Interactive and Discrete Optimizer) [10] [11]. This program throws the value of the minimized objective function as a result (the costs), as well as the decision variables that represent which it is complementary electrode system and grounding grid that should be selected to build the grounding system in way of fulfilling the system technical constraints (touch and step voltage). The diagram outlined for the proposed methodology is show in the figure 2 .

For the program (LINDO) can read the information, this should be in a predetermined format that is not more than an data arrangement following some rules preset by the program.

\section{TEST CASE}

The case study presented in this work was extracted of the reference [17]. The data are there exposed and can be asked to the authors, since by space limitations they were omitted. The dimension of the $115 / 13.8 \mathrm{kV}$ substation is $36 \times 40 \mathrm{~m}$.

Considerations of Optimization:

They are considered variable three geometric configurations of the Grounding grid, two possible conductors size (4/0 AWG and $250 \mathrm{kCMIL}$ ), two different depths for the grounding grid $(0.5$ and $0.6 \mathrm{~m})$ and three configurations of the complementary electrodes of the transmission line. The main objective is found an optimum or best solution (most minimum costs) of the grounding system for the substation.

The associated cost of each possible grounding grid, the complementary electrodes, the touch and step voltages are calculated through an Excel program and can be asked to the authors.

The possible configurations of the grounding grid are represented in the figure 3 .

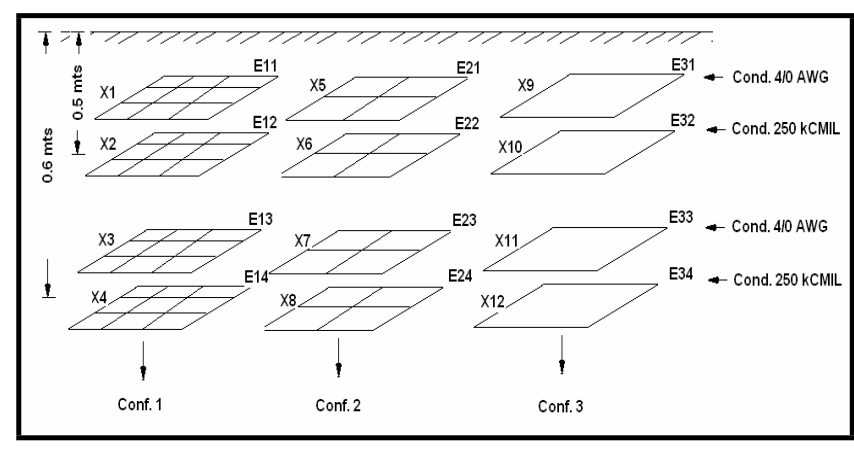

Fig.3. configurations of grounding grid to be considered

The mathematical formulation of the problem in LINDO format is show in the Table I.

This problem has 15 real variables that represent the costs in the objective function and 96 binary variables that represent the decision of the type of grid, the space among the conductor, and depth of installation, the type and size of conductor of the grounding grid.

The optimization problem was solved with LINDO Program obtaining the results are show in the Table II.

The solution of the presented problem throws us that the optimum design consists of a rectangle grid with $3 \mathrm{~m}$ separation conductors between itself and calibre $350 \mathrm{Kcmil}$, buried to $0.5 \mathrm{~m}$ of depth, with a configuration type rectangle installed in parallel to the transmission line. The total cost of this grounding system is of 56117 \$.

The solution of the presented problem without the use of optimization techniques, threw as a result a rectangle grid 
with $2 \mathrm{~m}$ space between parallel conductors and calibre 4/0 AWG, $0.5 \mathrm{~m}$ of depth. This solution represents an investment cost of 67726 \$. The savings obtained applying optimization technique is of $11609 \$$ that represents a $17 \%$.

\section{CONCLUSION}

Engineering design of grounding grid in substations is an iterative process that is facilitated if design systems attended by computer are used, which allows us to detect the best technical-economic results In this work outlined and solved an optimization problem that allows the optimum selection of grounding grid arrangement including the installation considerations of transmission line complementary electrodes, for condition of minimum investment cost fulfilling the technical constraints of the system (Allowed Touch and Step Voltage). The outlined model is based on the calculations for the grounding grid design described in the standard IEEE-802000 [1].

- Was developed a satisfactorily computational tool that:

- $\quad$ Considers all possible combinations of grounding grid configurations (geometry).

- $\quad$ Considers all the possible combinations of grounding grid depth

- Considers all the possible combinations of conductor size for grounding grid.

- Chooses the optimum complementary electrodes for transmission line and grounding grid to satisfy technical and economic requirements of the system in each application

The application of the proposed methodology to the design of the grounding grid of the Esmeralda substation shows the effectiveness of the method with a very small computational time and a reduced cost of the project.

\section{REFERENCES}

[1] J. Blandón, "State of the art in the substation grid grounding design" Electroporcelana GAMMA S.A. Technical Report N ${ }^{\circ} 161998$ (In Spanish).

[2] P. Ljubivoje, "Practical Method for Evaluating Ground fault Current Distribution in Station, Towers and Ground Wire," IEEE Trans. Power delivery, vol. 13, $\mathrm{N}^{\mathrm{o}}$ 1, January 1998.

[3] L. Hyung-Soo, K. Jung-Hoon, F. Dawalibi and M. Jinxi., "Efficient Ground grid Designs in Layered Soils," IEEE Trans. Power Delivery, vol. 13, No 3, July 1998

[4] F. Navarrina, L. Moreno, E. Bendito, A. M. Encinas, A. Ledesma, and M. Casteleiro, "Computer aided design of grounding grids: A boundary element approach," in Proc. 5th Eur. Conf. Math. Ind., M. Heiliö, Ed.,1991, pp. 307-314

[5] J. Hands Seeder, S. Arora and S. Soni, "A Practical Approach for Computation of Grid Current," IEEE Tans. Power Delivery, vol. 14, $\mathrm{N}^{\circ}$ 3, July 1999

[6] P. Ljubivoje, "Efficient Reduction of Fault Current through the Grounding Grid of Substation Supplied by Cable Line," IEEE Tans. Power Delivery, vol. 15, $\mathrm{N}^{\circ}$ 1, April 2000.

[7] E. Bendito, Á. Carmona, A.M. Encinas, and M.J. Jimenez, "The Extremal Charges Method in Grounding Grid Design," IEEE Trans. Power Delivery, vol. 17, $\mathrm{N}^{\circ}$ 1, January 2004.
[8] J.G. Aderson, "Lightning Performance of Transmission Line," Chapter 12, Transmission Line Reference Book, $345 \mathrm{kV}$ and above. Second Edition. EPRI-Electric Power Research Institute, Palo Alto, California, 1982.

[9] M. E. Van Valkenburg. "Network Analysis," 3rd ed. Prentice Hall of India Pvt. Ltd. New Delhi, 1984.

[10] L. Schrage, "User's Manual for Linear, Integer, and Quadratic Programming with LINDO,” Boyd \& Fraser publishing company. 1991.

[11] http: Ilwww.lindo.com

[12] V. De Andrade, "Engineering design of Esmeralada compact substation of 115/13.8 kV with numerical control," Thesis, USB, 2002 (In Spanish).

[13] J. Carmona y J. Fuentes, "Cost optimization of ground grids substation construction," 5th Generation and Transmission of Electrical Power System Conference (In Spanish).

[14] G. Pesse y D. Di Cecco, "Earth Potential transfer and its interaction with the ground grid arrangements of current emission and receiver," 5th Generation and Transmission of Electrical Power System Conference (In Spanish)

[15] D. Di Cecco y E. Gudiño, "Economic advantages to Install Arrangements of Steel grid grounding system," 5th Generation and Transmission of Electrical Power System Conference, 1989 (In spanish).

[16] IEEE Std. 80-2000, "IEEE Guide for Safety in AC Substation Grounding," IEEE: Institute of Electrical and Electronic Engineers, Inc. Nueva York, 2000.

[17] IEEE Std. 81-1983. "IEEE Guide for Measuring Earth Resistivity, Ground Impedance, and Earth Surface Potentials of a Ground System,' IEEE: Institute of Electrical and Electronic Engineers, Inc. New York, 1983.

\section{BIOGRAPHIES}

H. M. Khodr (M'99), received the Ph.D., M.Sc. and B.Sc. degrees in Electrical Engineering from the José Antonio Echeverría Higher Polytechnic Institute (ISPJAE) in 1997 and 1993 respectively.

$\mathrm{He}$ is a Professor of Electrical Engineering at Universidad Simón Bolívar (USB), Caracas, Venezuela. Presently, he is a Senior Researcher at INESC Porto, Portugal on leave of USB. His current research activities are concentrated in the planning, operation and economics of electrical power systems.

G. A. Salloum received the Electrical Engineering degree in 2002 from Universidad Simón Bolívar, Caracas, Venezuela.

Currently is with the Electrical Department of INELECTRA S.A.C.A, Caracas, Venezuela. His current research activities are concentrated on grounding practices, standards applicability optimum in oil projects and technological management.

Vladimiro Miranda (M'90-SM'04-F'05) received the graduation, Ph.D., and Agregado degrees in electrical engineering from the University of Porto, Porto, Portugalin 1977, 1982, and 1991, respectively.

In 1981, he joined the Faculty of Engineering, University of Porto and currently holds the position of Professor Catedrático. He is also currently Director of the Instituto de Engenharia de Sistemas e Computadores do Porto. He has authored many papers and been responsible for many projects in areas related with the application of computational intelligence to power systems. 